\title{
Segredo profissional e sua importância na prática de enfermeiros e odontólogos
}

Orlene Veloso Dias ${ }^{1}$, Ludmila Mourão Xavier Gomes ${ }^{2}$, Thiago Luis de Andrade Barbosa ${ }^{3}$, Luís Paulo Souza e Souza ${ }^{4}$, Antônio Lincoln de Freitas Rocha ${ }^{5}$, Simone de Melo Costa ${ }^{6}$

\begin{abstract}
Resumo
Este artigo apresenta a definição de segredo e sigilo profissional em saúde, bem como os critérios que os prescrevem, indicando sua importância para enfermeiros e odontólogos. Essas definições basearam-se em extensa pesquisa bibliográfica, incluindo a legislação, artigos eletrônicos em bases acadêmicas e literatura científica impressa. A discussão aponta que o sigilo nos serviços de saúde quanto às informações dos usuários é previsto em lei e pelos conselhos de ética profissional. Este arcabouço legal e normativo define o dever de lealdade do profissional para com o usuário, enfatizando a importância de preservá-lo. A discussão também mostra que o sigilo pode ser quebrado mediante autorização do usuário ou nas situações amparadas legalmente, consideradas como justa causa. Conclui indicando a necessidade de discutir o tema com os trabalhadores de saúde, visando instrumentalizá-los a adotar postura ética e moralmente correta, sendo o próprio texto uma iniciativa no sentido de prover tal informação.
\end{abstract}

Palavras-chave: Privacidade. Comunicação sigilosa. Ética.

\section{Resumen}

\section{El secreto profesional y su importancia en la práctica de los enfermeros y odontólogos}

Este artículo presenta la definición de secreto y sigilo profesional en salud, así como los criterios que los prescriben, indicando su importancia para los enfermeros y odontólogos. Estas definiciones se basaron en una extensa investigación bibliográfica, incluyendo la legislación, artículos electrónicos en bases académicas y literatura científica. La discusión señala esa confidencialidad en los servicios de salud como la información de los usuarios es prevista por la ley y por el Consejo de Ética profesional. Este marco legal y normativo define el deber profesional de lealtad hacia el usuario, haciendo hincapié en la importancia de preservarlo. La discusión también muestra que el sigilo puede ser roto con el permiso del usuario o en situaciones apoyadas legalmente considerado como causa justa. Concluye indicando la necesidad de discutir el tema con los trabajadores de la salud, enfocando instrumentalizarlos a adoptar una postura ética y moralmente correcta, siendo el propio texto una iniciativa para proporcionar dicha información.

Palabras-clave: Privacidad. Confidencialidad. Ética.

\section{Abstract \\ The professional secret and its importance to nurses and dentists pratice}

This article presents the definition of secrecy and professional secrecy in health area, as well as the criteria which prescribe it, indicating its importance for nurses and dentists. These definitions were based on extensive bibliographical research, including the legislation, electronic items in academic databases and printed literature. The discussion points out that confidentiality in health services regarding the information of the users is provided by law and by the advice of professional ethics. This legal and normative framework defines the professional duty of loyalty towards the user, emphasizing the importance of preserving it. The discussion also shows that secrecy can be broken with the permission of the user or in situations supported legally considered as just cause. It concludes by indicating the need to discuss the issue with health workers with the aim of instrumentalizing them to adopt an ethical and morally correct posture, being the actual text a initiative to provide such information.

Key words: Privacy. Confidentiality. Ethics.

1. Mestre orlenedias@yahoo.com.br 2. Doutoranda ludyxavier@yahoo.com.br 3. Doutorando tl andrade@yahoo.com.br 4. Pósgraduando luis.pauloss@hotmail.com 5. Graduando antonio.lincoln@hotmail.com 6. Doutora smelocosta@gmail.com - Universidade Estadual de Montes Claros, Montes Claros/MG, Brasil.

\section{Correspondência}

Luís Paulo Souza e Souza - Rua Córsega, 26, bloco 4, aptº 302, Ibituruna CEP 39402285. Montes Claros/MG, Brasil.

Declaram não haver conflito de interesse. 
A vida humana implica em inter-relação. Ao viver em sociedade as pessoas necessitam umas das outras, o que caracteriza a própria essência do processo social. As regras implícitas e explícitas que organizam esse processo definem tanto a posição dos interlocutores quanto aquilo que se espera de cada indivíduo. São definidos os comportamentos esperados entre pais e filhos, nas diferentes etapas da vida de cada um, de subalternos e superiores, na relação profissional e nas expectativas entre governantes e governados na esfera pública.

$\mathrm{Na}$ área da saúde, o fenômeno se manifesta no contato diário entre profissional e paciente. Diferentemente do que ocorre em outras relações sociais, objetiva um resultado: a cura. Este processo é ancorado na troca de informações, conselhos e cuidados de saúde entre os profissionais e pacientes, considerando as dimensões mental, física e espiritual. No intento de que a relação cumpra seu objetivo, o profissional deve, com base em seu conhecimento, colocar-se à disposição do paciente com vistas a ajudá-lo a discernir o caminho para promover, prevenir ou recuperar os agravos ou distúrbios de saúde que o incomodam. Este, por sua vez, procura o profissional para usufruir de seu conhecimento e obter conforto pessoal ou familiar, bem como definir o tratamento efetivo para os problemas de saúde que o estejam atingindo.

Para que desse relacionamento surta o efeito esperado, é importante que o paciente franqueie ao profissional detalhes sobre sua vida e rotinas, a fim de que este possa entender a natureza e a causa do problema, ou seja, que elabore o diagnóstico. Nesse processo, surgem revelações de fatos, muitas vezes, de caráter íntimo, que os confidentes não pretendem que sejam revelados. Trata-se de um princípio natural de confiança, respeito e dignidade que o confidente transfere para o confiado. Na maioria dos casos, esses fatos não apresentam maior relevância social ou pessoal. Entretanto, existem aqueles que necessitam ser mantidos em absoluto sigilo, pois sua revelação poderá causar sérios danos ou prejuízos materiais ou morais. Por essas razões, tutela-se a liberdade individual relacionada à inviolabilidade dos segredos, no que tange à oferta de serviços de saúde ${ }^{1,2}$.

A questão referente ao sigilo profissional e confidencialidade de informações dos usuários do serviço de saúde é de fundamental importância para uma adequada assistência. $O$ que requer dos profissionais envolvidos (médicos, enfermeiros, dentistas, técnicos administrativos, entre outros) formação idônea para lidar com os aspectos dire- tamente ligados ao resguardo de informações e dados do paciente. Diversos instrumentos abordam o tema, como, por exemplo, o Código Penal, o Código de Ética dos Profissionais de Enfermagem, o Código de Ética dos Profissionais de Odontologia e o Código de Ética Médica, os quais possuem normas específicas para o tema do segredo profissional, estabelecendo direitos e deveres dos profissionais em diversas situações e contextos ${ }^{3-5}$.

É de extrema importância manter segredo das informações do cliente, nas situações adequadas, e preservar sua privacidade, o que remete a questões de ética e moral, bem como aspectos relacionados à humanização dos serviços. Deve-se considerar que, em se tratando de privacidade, não importa cor, sexo ou orientação sexual do paciente. É um aspecto que deve contemplar, inclusive, a dimensão etária, estendendo-se desde os recém-nascidos até as pessoas idosas ${ }^{6}$. Na sociedade atual, há um conjunto muito vasto de informações a respeito dos indivíduos e das instituições para viabilizar o atendimento aos pacientes, planejar a alocação de recursos e a gestão de serviços de saúde, entre outras funções. Ante tantas informações, obtidas das mais diversas formas, ampliam-se as possibilidades e os riscos do uso indevido e de quebra de privacidade de indivíduos e, mesmo, de instituições.

Discutir esses aspectos direcionando as abordagens para a área da enfermagem e da odontologia é de significativa relevância, pois esses profissionais, em especial os enfermeiros e dentistas, lidam diretamente com essas questões na maior parte do seu tempo. Ainda mais considerando-se que os profissionais de enfermagem e os odontólogos estão em constante contato com o usuário, sendo responsáveis por atender grande parte de suas necessidades e, portanto, constituindo parte indispensável para uma assistência de qualidade. Desse modo, o presente trabalho objetiva a revisão bibliográfica sobre o segredo profissional relacionado a estas categorias de profissionais de saúde.

\section{Método}

Realizou-se revisão bibliográfica a partir das publicações disponíveis nas principais bases de dados: SciELO, Medline, Lilacs e Biblioteca Virtual em Saúde (BVS). As buscas utilizaram os descritores "Segredo profissional", "Sigilo profissional", "Comunicação sigilosa", "Privacidade das informações" e "Confidencialidade das informações", estendendose a publicações dos últimos 12 anos (2001-2012). 
Após a pesquisa com os descritores, os artigos foram identificados por área temática, ano, autores e resumos - e somente então selecionados aqueles que se enquadravam ao objetivo desta pesquisa.

Para fomentar a discussão acerca dos princípios deontológicos que regem a confidencialidade, primeiramente foram analisados o Código de Ética dos Profissionais de Enfermagem, o Código de Ética dos Profissionais de Odontologia e o Código Penal. Como referencial norteador foi utilizada a literatura científica da área de segredo profissional relacionado a estas categorias de profissionais de saúde; livros-textos contemporâneos de especialistas sobre o tema, os quais, na maioria, trazem exemplos de problemas relacionados à manutenção da confidencialidade na esfera profissional. Posteriormente à pesquisa bibliográfica, realizou-se a seleção e leitura dos artigos e livros-textos, de forma reflexiva, buscando discutir a problemática que envolve o segredo profissional.

Os critérios de inclusão para seleção das publicações foram: artigos e livros-texto na temática de segredo profissional relacionado às categorias profissionais de enfermagem e odontologia; que estivessem em português; publicados no período delimitado; disponíveis na íntegra, na forma impressa e eletronicamente, para leitura. Ao término, o universo do estudo contou com 17 trabalhos.

\section{Resultados e discussão}

\section{Profissionais de saúde e o segredo profissional}

A privacidade consiste no conjunto de informações sobre uma pessoa, que pode decidir mantê-las sob seu exclusivo controle ou comunicá-las, decidindo em que medida e a quem, quando, onde e em que condições o outro poderá acessá-las. Por sua vez, a confidencialidade se relaciona com a garantia (no sentido de confiança) de que as informações prestadas não serão reveladas sem prévia autorização da pessoa que as confiou. A privacidade das informações é um direito dos usuários dos serviços de saúde, ao mesmo tempo em que a confidencialidade é um dever dos profissionais em relação às informações geradas e confiadas na relação profissional-paciente ${ }^{7,8}$.

O segredo profissional adquiriu fundamentação mais rigorosa ao ser centralizado na necessidade e direito do cidadão à intimidade, passando a ser entendido como confidencialidade. Esta dupla natureza do conceito de segredo profissional transforma-o num direito-dever, à medida que, sendo direito do paciente, gera uma obrigação específica aos profissionais de saúde ${ }^{9}$. Qualquer informação fornecida por pacientes na ocasião de seu atendimento no hospital, posto de saúde ou consultórios privados, bem como as provenientes de resultados de exames e procedimentos realizados com finalidade diagnóstica ou terapêutica são de sua exclusiva propriedade.

Mas nem sempre isso foi assim interpretado. Houve, durante muito tempo, a percepção de que tais informações pertenciam ao médico ou à instituição de saúde. Daí decorrem as denominações "prontuário médico" e "arquivo médico", até hoje comumente encontradas. Na verdade, os trabalhadores de saúde e as instituições são apenas depositários dessas informações, o que traduz a necessidade de atualizar a forma como são tratadas as informações do usuário. $O$ que justifica o acesso às informações contidas no prontuário é a necessidade profissional, e qualquer um que delas faça uso não tem o direito de utilizá-las livremente, o que traduz um direito ao acesso somente às informações que efetivamente contribuam para o atendimento do paciente ${ }^{10,11}$.

O profissional de enfermagem, em seu contato diário com pacientes, familiares e funcionários, depara-se com informações que não pode revelar e outras que pode ou mesmo deve revelar. Mas como saber o que revelar ou não? E a quem? São questões levantadas principalmente considerando-se que esse assunto diz respeito a aspectos humanos, jurídicos e deontológicos. O segredo fundamentase na confiança, na confidência e na justiça. $E$ ao se guardar ou revelar um segredo indevidamente, respeita-se ou desrespeita-se a justiça, tendo em vista que a informação pertence ao usuário do serviço ${ }^{6,10}$. Portanto, em qualquer especialidade da atenção à saúde é importante refletir sobre as implicações éticas da relação terapêutica, considerando se os pacientes estão sendo respeitados em relação à confidencialidade das informações obtidas durante 0 atendimento ${ }^{5-9}$.

O dever ético e legal dos profissionais de saúde tem origem justamente na garantia da privacidade e confidencialidade das informações dos pacientes, mantendo, desse modo, o sigilo das informações. O segredo profissional no trabalho de assistência à saúde é evidenciado no pensamento hipocrático, que afirmava: As coisas que eu verei ou ouvirei dizer no exercício da minha arte, ou fora de minhas funções, no comércio dos homens, e que não deverão ser divulgadas, eu calarei, percebendo-as como segredos invioláveis ${ }^{12-14}$. 


\section{Segredo profissional x sigilo profissional}

A definição dicionarizada dos termos sigilo e segredo é mutuamente referente, sendo cada uma destas palavras remetida a outra para a definição de significado. Entretanto, muitas vezes esses termos são utilizados de forma inadequada. A palavra "segredo" pode significar simplesmente ocultação ou preservação de informações, as quais dizem respeito à intimidade da pessoa e, nessa condição, devem ser mantidas e preservadas de forma idônea. A denominação "sigilo" tem sido cada vez menos utilizada e seu uso nos diferentes idiomas está relacionado a aspectos de ocultação, sendo por isso menos utilizada no sentido de preservação de informações ${ }^{10}$.

$\mathrm{Na}$ área da saúde, a diferenciação mais atual entre segredo e sigilo profissional consiste em definir segredo como tudo aquilo que não pode ser revelado, enquanto sigilo seria característico das relações de confiança, haja vista que as profissões desta área se estruturam essencialmente nessa prerrogativa. Poder-se-ia então dizer que o sigilo profissional é relativo ao atendimento por profissionais da área da saúde e o segredo profissional diz respeito àqueles profissionais de outra formação que trabalham em instituições de saúde e, portanto, têm acesso a informações de pacientes - por exemplo, as pessoas que ocupam funções administrativas nos serviços de saúde ${ }^{15}$.

A manutenção do segredo profissional deve ser o comportamento adotado pela totalidade dos envolvidos em práticas sanitárias, não sendo exclusivo daqueles que executam as atividades-fim da área, como dentistas, enfermeiros, médicos, psicólogos, psicanalistas, fonoaudiólogos, fisioterapeutas, entre outros. É uma obrigação ético-legal concernente a todos os que atuam nos serviços de saúde, estendendo-se ao corpo técnico-administrativo, mesmo àqueles cujas profissões não estejam sob controle de normas deontológicas ou de conselhos de ética profissional ${ }^{13}$. O caráter sigiloso das informações deve ser observado tanto em comunicações orais quanto escritas com os profissionais, com a imprensa ou mesmo com autoridades; o sigilo aplicase, dessa forma, em cartas, divulgações à imprensa, boletins médicos, discussões de casos, conferências e congressos com exibição de imagens, fotografias, radiografias - e nas perícias e auditorias ${ }^{13}$.

A estrutura atualmente desenhada para fornecer serviços de saúde implica na ideia de integralidade, em trabalho multiprofissional que agregue profissionais de diferentes áreas da saúde. Contudo, o trabalho multiprofissional não deve implicar em que todos os membros da equipe devam ter aces- so a totalidade das informações do paciente. Se o intercâmbio de informações é necessário, deve ser limitado àquelas que cada profissional necessita para desenvolver suas atividades em benefício do paciente. A privacidade e o sigilo profissional são instrumentos multiprofissionais e abrangem não apenas enfermeiros, médicos e dentistas, mas também outras categorias profissionais.

Estudo realizado acerca do trabalho do agente comunitário de saúde demonstrou que seu contato frequente com os usuários propicia o desenvolvimento de forte relação de confiança. Por amiúde receber o profissional em sua casa, o usuário se sente à vontade e revela aspectos de suas condições de saúde, inclusive até antes de comunicar os mesmos fatos aos outros componentes da equipe de saúde. Isso pode levar a um impasse ético para os profissionais, à medida que gera um problema pertinente ao posicionamento do próprio agente comunitário, haja vista este ser morador da comunidade. Nessa perspectiva, questiona-se: como preservar as informações do paciente enquanto morador de uma determinada comunidade e enquanto vizinho? ${ }^{1,15}$ Esta questão controversa ainda não foi totalmente dirimida e vem sendo debatida nos meios acadêmico e profissional, considerando a especificidade da atuação e a ambiguidade do papel do agente de saúde.

O que se tem demarcado até o momento quanto a esta delicada questão é que "segredo profissional" é tudo aquilo que por sua natureza deve ser conservado oculto, desde que a manutenção do sigilo não acarrete danos àquele a quem o segredo pertence ou a outras pessoas. É função dos profissionais de saúde estabelecer condições para que o usuário possa decidir quais informações quer manter em segredo e quais quer comunicar aos familiares, amigos ou aos próprios profissionais de saúde ${ }^{11}$. É importante ressaltar que em determinadas situações, como, por exemplo, informações que podem causar danos a terceiros ou situações de cunho epidemiológico grave, a literatura e a legislação estabelecem a necessidade da quebra da confidencialidade. Tais situações serão descritas e debatidas a seguir.

\section{Segredo profissional: manter ou revelar?}

A manutenção do segredo está vinculada tanto à questão da privacidade quanto da confidencialidade. Em se tratando de privacidade, o profissional tem o dever de resguardar as informações que teve contato e preservar o paciente, o que se traduz até mesmo num dever institucional. Já a confidencialidade pressupõe que o usuário repasse as informações diretamente ao profissional, sendo 
este responsável pela preservação das mesmas. A palavra "confidencialidade" tem origem no termo "confiança", condição fundamental para o bom relacionamento terapêutico. O usuário confia que o enfermeiro, o médico ou o dentista preservarão tudo o que lhe for dito, tanto que, muitas vezes, até mesmo as pessoas que lhes são mais próximas não têm conhecimento dessas informações ${ }^{10,11}$.

O segredo profissional é passível de ser revelado de forma direta ou indireta. Diz-se que a revelação é direta quando são publicados o conteúdo e o nome da pessoa a quem pertence o segredo; e indireta se forem oferecidos indicativos para o conhecimento do segredo e identificação do seu dono. Embora a revelação seja direta ou indireta, a (in)justiça é praticada da mesma forma e as responsabilidades jurídica e deontológica se fazem presentes nas situações. Existem circunstâncias nas quais o segredo pode ser revelado e outras em que deve ser manifestado a quem tem o direito. A importância desse aspecto reside no fato de que o profissional pode ser processado ou ferir a deontologia revelando ou guardando um segredo ${ }^{16}$.

No que tange especificamente às categorias profissionais analisadas neste trabalho - enfermeiros e odontólogos -, a normatização prevista em seus códigos deontológicos é explicita e não deixa margem a dúvidas. O Código de Ética dos Profissionais de Enfermagem traz em seu art. 81 o direito do profissional de não revelar as informações confidenciais de que tenha conhecimento em virtude do seu exercício profissional a pessoas ou entidades que não estejam obrigadas ao sigilo ${ }^{4}$. Enquanto responsabilidades e deveres, o art. 82 determina que se deve manter segredo sobre fato sigiloso de que tenha conhecimento em razão de atividade profissional, exceto nos casos previstos em lei, ordem judicial ou consentimento por escrito da pessoa envolvida ou de seu representante legal ${ }^{4}$. Estabelece-se também, no art. 83, ser dever do enfermeiro orientar sua equipe sobre o sigilo profissional ${ }^{4}$.

Ainda de acordo com o Código de Ética dos Profissionais de Enfermagem, é proibido a estes profissionais franquear o acesso de informações e documentos a pessoas não diretamente vinculadas à prestação da assistência, excetuando-se os casos previstos em lei ou por ordem judicial (art. 84), e divulgar ou mesmo fazer referência a casos, situações ou fatos de forma que os envolvidos possam ser reconhecidos (art. 85) ${ }^{4}$.

Com o intuito de zelar e promover o bom conceito da profissão odontológica, os membros do Conselho Federal e dos conselhos regionais de Odontolo- gia elaboraram, em 1976, o primeiro Código de Ética Odontológica (CEO), estabelecendo os princípios fundamentais que direcionam a conduta do cirurgião-dentista no exercício da profissão. Recentemente, em 2012, o código foi atualizado e o Capítulo VI trata especificamente do sigilo profissional ${ }^{5}$.

O Código de Ética Odontológica traz em seu Capítulo VI, art. 14, inciso I, o direito de o profissional não revelar, sem justa causa, fato sigiloso ou informações confidenciais de que tenha conhecimento em razão do exercício profissional a pessoas ou entidades não obrigadas ao sigilo. Enquanto responsabilidades e deveres, o parágrafo único determina que se deve manter segredo sobre fato sigiloso de que tenha conhecimento em razão de atividade profissional, exceto nos casos de notificação compulsória; casos previstos em lei, ordem judicial; perícia odontológica nos seus exatos limites; estrita defesa de interesse legítimo dos profissionais inscritos; ou com consentimento, por escrito, da pessoa envolvida ou de seu representante legal ${ }^{5}$.

Na dimensão legal, o Código Penal, em seu art. 153, define ser crime divulgar, sem justa causa, conteúdo de documento particular ou correspondência confidencial, de que é destinatário ou detentor, e cuja divulgação possa produzir dano a outrem. O art. 154 presume ser crime revelar a alguém, sem justa causa, segredo de que tem ciência em razão de função, ministério, ofício ou profissão e cuja revelação possa produzir dano a outrem ${ }^{3}$. Desse modo, a própria legislação define que as instituições devem proteger os documentos que possuem registros com informações de seus pacientes. No tocante à dinâmica de serviços multiprofissionais, incluindo nestes os profissionais que não atuam em áreas-fim, devem ser estabelecidas e sempre aprimoradas normas e rotinas de restrição de acesso aos prontuários e de utilização de senhas de segurança em sistemas informatizados. $\mathrm{O}$ acesso de terceiros envolvidos no atendimento, a exemplo das seguradoras e outros prestadores de serviços, deve merecer especial atenção ${ }^{10}$. Quando se revela, indevidamente, um segredo profissional, desrespeita-se a confiança depositada e pode-se ocasionar grave prejuízo ao bom nome, à honra ou à profissão ${ }^{16}$.

Porém, o direito à privacidade e à confidencialidade dos dados não é considerado absoluto, tanto ética quanto legalmente. A quebra do sigilo pode acontecer devido ao próprio consentimento do paciente ou de seu representante legal, por dever legal ou mesmo pela existência de uma "justa causa" ${ }^{13}$. A legislação prevê as situações nas quais o segredo deve ser revelado. Dentre estas: 1) quando se tra- 
tar de uma declaração de nascimento; 2) evitar um casamento, nos casos em que patologias possam pôr em risco um dos cônjuges ou a prole; 3) na declaração de doenças de notificação compulsória; 4) fato delituoso previsto em lei; 5) caso de sevícias de menores; 6) conhecimento de abortadores profissionais; 7) nas perícias médico-legais e nos registros de livros hospitalares. Pode-se revelar o segredo, ainda, quando o dono permite; quando o bem de terceiros o exige; quando o bem do depositário o exige ou quando o bem comum o exige.

Fica nítido, portanto, que a quebra do sigilo pelo profissional pode ocorrer sob o amparo da legislação em situações onde haja justa causa, como aquelas compatíveis com a gravidade da informação. Alinha-se neste pressuposto a notificação à autoridade competente sobre a existência de doenças ou situações de informação compulsória; maus tratos em crianças ou adolescentes, abuso de cônjuge ou idoso e ferimento por arma de fogo ou outro tipo de arma, quando se suspeita que a lesão tenha ocorrido em função de ato criminoso.

A legislação estende a confidencialidade aos casos em que o profissional é intimado a testemunhar em corte judicial. Mesmo nestas circunstâncias, ele deve declarar-se impedido de revelar qualquer informação, pois está eticamente comprometido com seu resguardo. No entanto, existem situações em que um juiz pode assumir a responsabilidade e requerer a revelação das informações, mesmo que isso contrarie o que estabelece o código de ética profissional, desde que tal fato fique claramente registrado nos autos do processo, o que caracteriza uma exceção e não a mera quebra da confidencialidade. Esse caminho pode corresponder aos aspectos legais do ato de revelar informações caracterizadas como confidenciais, mas não contempla plenamente os aspectos morais e éticos envolvidos ${ }^{10,17}$. Nas situações em que ocorre a quebra de privacidade ou confidencialidade deve ficar claro o dever de lealdade do profissional para com o paciente, sendo de extrema importância que tal compromisso seja preservado, ainda que o usuário esteja inconsciente - ou mesmo após sua morte.

Ocultar fato de que se tem ciência, mas que deveria ser revelado, pode igualmente infringir a Justiça e o direito comunitário. Por exemplo, quando um cliente revela a um profissional de saúde que possui doença contagiosa de notificação compulsória, tal segredo não deve ser mantido, pois coloca em risco a saúde da comunidade. Ante situações como essa, evidencia-se a importância de conhecer as determinações legais para saber avaliar quando é preciso revelar ou guardar um segredo ${ }^{13}$.

Ao analisar a questão do segredo profissional, constata-se a existência de aspectos jurídicos e deontológicos. Comumente, dá-se mais importância aos primeiros - à infração legal -, deixando de lado as questões deontológicas, consideradas de menor importância. Tal constatação revela ser necessária uma mudança de postura, pois ao violar um segredo desobedecem-se leis, mas também se violam aspectos fundamentais das relações humanas: o respeito, a justiça, a confiança e a confidência ${ }^{16}$.

Todas as situações que envolvem o segredo profissional devem ser enfrentadas com sabedoria, considerando-se tanto as previsões legais quanto os princípios formais e informais que regem as relações pautadas na confiança. É fundamental reconhecer a dignidade das pessoas, independentemente de sua idade, sexo ou capacidade, pois todas merecem respeito e cuidado, incluindo-se neste o resguardo das informações a elas pertinentes ${ }^{10}$. Sobressai-se, assim, o respeito ao paciente em todos os aspectos, sobretudo àqueles relacionados às informações prestadas e a seus dados pessoais, inerentes a sua história de vida e definição como pessoa em sociedade.

\section{Considerações finais}

Fica patente a importância de se considerar a problemática relativa à questão do segredo e sigilo profissional, para o aprimoramento dos serviços de saúde. Constata-se que há obrigação dos profissionais e serviços de saúde adotarem medidas para minimizar as violações dos princípios éticos e garantir o caráter sigiloso das informações, sendo tal obrigação invariável, ou seja, aplica-se tanto a serviços públicos como privados, em âmbito ambulatorial ou hospitalar, em convênios ou serviços gratuitos. Portanto, os profissionais de saúde precisam ter sempre em mente que só têm autorização para acessar as informações sobre os pacientes em decorrência de sua função laboral, em trabalho clínico ou administrativo. Mesmo considerando que a manutenção da confidencialidade não é absoluta, precisam estar cientes de que só é legalmente permitida em situações particulares.

Ao longo deste trabalho procurou-se deixar clara a importância do tema, tanto no âmbito acadêmico, relativo à formação dos futuros profissionais, quanto no que diz respeito à própria atuação das diversas categorias nos serviços de saúde. Neste sentido, é indispensável enfatizar a necessidade de estimular e promover discussões acerca do assun- 
to, na formação e nas próprias instituições laborais, para que os trabalhadores de saúde, como um todo, conheçam seus direitos e deveres, assumindo a postura adequada ante as mais diversas ocasiões. Fazse necessário aprofundar seu conhecimento para instrumentalizá-los quanto aos ditames legais e às normas consensuais, com vistas à adoção de postu- ras eticamente corretas e moralmente adequadas, frente a situações conflituosas. Este processo de formação e capacitação contínuas facilitará sobremaneira o entendimento dos problemas, os quais, muitas vezes, podem instigar no profissional de saúde sérias dúvidas, tornando sua conduta inadequada ou insegura.

\section{Referências}

1. Seoane AF, Fortes PAC. A percepção do usuário do programa saúde da família sobre a privacidade e a confidencialidade de suas informações. Saúde Soc. 2009;18(1):42-9.

2. Ferreira RC, Silva RF, Zanolli MB, Braz $M$, Varga CRR. Relações éticas na atenção básica em saúde: a vivência dos estudantes de medicina. Cienc. Saúde Coletiva. 2009; 14(1):1.533-40.

3. Brasil. Lei $n^{\circ} 2.848$, de 7 de dezembro de 1940. Código penal. Diário Oficial da União. $31 \mathrm{dez}$. 1940 (acesso 10 mar. 2013). Disponível: http://www.planalto.gov.br/ccivil_03/decreto-lei/ Del2848compilado.htm

4. Brasil. Conselho Federal de Enfermagem. Resolução $n^{\circ} 311$, de 8 de fevereiro de 2007. Aprova a reformulação do Código de Ética dos Profissionais de Enfermagem. Diário Oficial da União. 13 fev. 2007;(31):Seção I, p. 81.

5. Brasil. Conselho Federal de Odontologia. Resolução $n^{\circ}$ 118, de 11 de maio de 2012. Revoga o Código de Ética Odontológica aprovado pela Resolução CFO-42/2003 e aprova outro em substituição. Diário Oficial da União. 14 jun. 2012;(114):Seção I, p. 118.

6. Freitas GF, Oguisso T, Fernandes MFP. Fundamentos éticos e morais na prática de enfermagem. Enferm. foco. 2010;1(3):104-8.

7. Massarollo MKB. Autonomia, privacidade e confidencialidade. In: Oguisso T, Zoboli ELCP, organizadores. Ética e bioética: desafios para a enfermagem e a saúde. São Paulo: Manolle; 2006. p. 136-52.

8. Loch JA, Clotet J, Goldim JR. Privacidade e confidencialidade na assistência à saúde do adolescente: percepções e comportamentos de um grupo de 711 universitários. Rev Assoc Med Bras. 2007;53(3):240-6.

9. Sales-Peres SHC, Sales-Peres A, Fantini AM, Freitas FD'AR, Oliveira MA, Silva OP et al. Sigilo profissional e valores éticos. RFO UPF. 2008;13(1):7-13.

10. Francisconi CF, Goldim JR. Aspectos bioéticos da confidencialidade e privacidade. In: Costa SIF, Oselka G, Garrafa V, organizadores. Iniciação à bioética. Brasília: Conselho Federal de Medicina; 1998. p. 269-84.

11. Abdalla FTM, Nichiata LYI. A abertura da privacidade e o sigilo das informações sobre o HIV/Aids das mulheres atendidas pelo programa saúde da família no município de São Paulo, Brasil. Saúde Soc. 2008;17(2):140-52.

12. Gobbetti GJ. A função da confidencialidade: bioética e incesto. [tese]. [Internet]. São Paulo: Universidade de São Paulo; 2006 (acesso 10 mar. 2013). Disponível: http://www.teses.usp.br/ teses/disponiveis/5/5160/tde-11102006-104710/

13. Fortes PAC. Ética e saúde: questões éticas, deontológicas e legais, tomada de decisões, autonomia e direitos do paciente, estudo de casos. São Paulo: EPU; 1998.

14. Freitas GF, Oguisso T, Merighi MA. Ethical events in nursing: daily activities of nurse managers and nursing ethics committee members. Rev Lat Am Enfermagem. 2006;14(4):497-502.

15. Fortes PAC, Spinetti SR. O agente comunitário de saúde e a privacidade das informações dos usuários. Cad Saude Publica. 2004; 20(5):1.328-33.

16. Gelain I. Deontologia e enfermagem. $3^{\mathrm{a}}$ ed. São Paulo: EPU; 1998.

17. Melo Costa S, Dias OV, Canela JR, Drumond JGF, Santa-Rosa TTA. Visão de discentes sobre atendimento a pacientes HIV/Aids. Arq Cent Estud Curso Odontol Univ Fed Minas Gerais. 2009;45(1):10-15.

\section{Participação dos autores}

Orlene Veloso Dias e Antônio Lincoln de Freitas Rocha trabalharam na concepção, análise e interpretação dos dados e redação do artigo. Luís Paulo Souza e Souza, Ludmila Mourão Xavier Gomes, Thiago Luis de Andrade Barbosa e Simone de Melo Costa trabalharam na análise e interpretação dos dados, redação do artigo e revisão crítica.

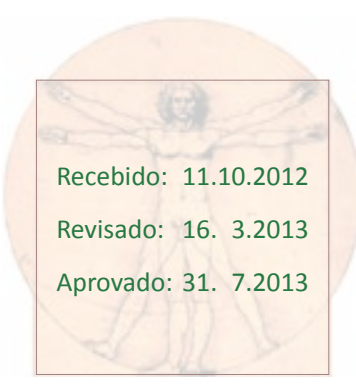

